Review Article

\title{
The Funds of Knowledge Approach: An Opportunity to Access Education for Ethnic Minority Students in Vietnam
}

\author{
Tran Thi Thanh $\mathrm{Ha}^{*}$ \\ Yen Bai Teachers' Trainning College, Dong Tam, Yen Bai City, Yen Bai, Vietnam
}

Received 22 July 2021

Revised 17 August 2021; Accepted 18 August 2021

\begin{abstract}
The funds of knowledge approach has been increasingly studied and applied to teaching practices in many developed countries. Learning about students' funds of knowledge and incorporation into their learning enables teachers to increase relevant learning experiences, empowering a socio-constructivist approach to teaching and learning. It is acknowledged to help students learn meaningfully by connecting lessons to students' funds of knowledge, especially to ethnic minority students, color, immigrant students, or disadvantaged students. However, there is a lack of studies and papers on the funds of knowledge approach in education in Vietnam. This article aims to introduce this educational approach and contribute to solving the challenges that ethnic minority education in Vietnam is facing. The article also suggests further studies to promote the application of the Funds of knowledge approach in Vietnam, thereby improving the quality of ethnic minority education in Vietnam and value the cultural resources, languages, and local knowledge of ethnic minority groups in Vietnam.
\end{abstract}

Keywords: Knowledge outside the school, funds of knowledge, teaching, learning, students, parents, community, teachers, multicultural education, ethnic minority students.

\footnotetext{
* Corresponding author.

E-mail address: tranha310yb@gmail.com
}

https://doi.org/10.25073/2588-1159/vnuer.4557 


\title{
Giáo dục dựa vào quỹ tri thức của học sinh: Cơ hội cho giáo dục học sinh dân tộc thiểu số ở Việt Nam
}

\author{
Trần Thị Thanh Hà* \\ Truoòng Cao đẳng Su phạm Yên Bái, Đồng Tâm, Thành Phố Yên Bái, Yên Bái, Việt Nam \\ Nhận ngày 22 tháng 7 năm 2021 \\ Chỉnh sửa ngày 17 tháng 8 năm 2021; Chấp nhận đăng ngày 18 tháng 8 năm 2021
}

\begin{abstract}
Tóm tắt: Cách tiếp cận giáo dục dựa vào quỹ tri thức của học sinh (Funds of knowledge) đã và đang được nghiên cứu và đưa vào ứng dụng trong nhà trường ở nhiều quốc gia phát triển. Thông qua việc khai thác và sử dụng quỹ tri thức ngoài trường học của học sinh và các hộ gia đình, và đưa vào trong dạy học, cách tiếp cận này được xem là phương pháp quan trọng nhằm thu hẹp khoảng cách bất bình đẳng giáo dục cho học sinh dân tộc thiểu số (DTTS), da mầu, học sinh nhập cư, hoặc xuất thân từ tầng lớp có thu nhập trong xã hội. Bài viết dựa trên sự tổng hợp các nghiên cứu khoa học về cách tiếp cận giáo dục này với mục đích giới thiệu một cách tiếp cận giáo dục mới, tiên tiến và góp phần vào giải quyết những thách thức mà giáo dục DTTS Việt Nam đang phải đối mặt. Bài viết cũng gợi ý những hướng nghiên cứu dựa trên cách tiếp cận này nhằm góp phần nâng cao chất lượng giáo dục DTTS và miền núi ở Việt Nam, đồng thời phát huy các giá trị văn hoá, ngôn ngữ, tri thức địa phương của cộng đồng DTTS.
\end{abstract}

Tù khóa: Tri thức ngoài nhà trường, quỹ tri thức, dạy học, học sinh, cha mẹ, cộng đồng, giáo viên, giáo dục đa văn hoá, dân tộc thiểu số.

\section{1. Đặt vấn đề}

Mặc dù Việt Nam đã đạt được phổ cập giáo dục tiểu học và có nhiều nỗ lực trong thu hẹp khoảng cách bất bình đẳng trong giáo dục, tuy nhiên chất lượng giáo dục ở vùng DTTS và miền núi vẫn còn thấp và đang phải đối mặt với nhiều thách thức trong việc tiếp cận giáo dục [1-4].

Thảo luận về chiến lược và kế hoạch giảm bất bình đẳng về chất lượng giáo dục giữa nhóm DTTS và đa số (người Kinh) ở Việt Nam đã nêu rõ rằng phát triển năng lực giáo viên và phương pháp sư phạm dựa trên việc đề cao ngôn ngữ bản địa, kiến thức văn hóa, bản sắc và kinh nghiệm trong đời sống hàng ngày của học sinh DTTS là một yêu cầu chính sách quan trọng của nhà nước và chính phủ Việt Nam $[5,6]$.

\footnotetext{
* Tác giả liên hệ.

Địa chỉ email: tranha310yb@gmail.com

https://doi.org/10.25073/2588-1159/vnuer.4557
}

Chính phủ Việt Nam đã có nhiều nỗ lực trong việc phát triển các chính sách giáo dục cho học sinh DTTS trong đó tập trung vào việc nhận biết và đánh giá các khía cạnh văn hóa và các nguồn lực của cộng đồng DTTS phục vụ cho mục tiêu giáo dục. Cụ thể thông qua một số dự án quy mô quốc gia như: Dự án giáo dục song ngữ trên cơ sở tiếng mẹ đẻ [7]; Khai thác nguồn tài nguyên văn hoá DTTS [8]; Trợ giảng cho học sinh dân tộc thiểu số [8]; Dự án dạy học Tiếng Mông cho giáo viên người Kinh [9].

Nghị quyết 29-NQ/TW năm 2013 về đổi mới căn bản, toàn diện giáo dục và đào tạo đã nhấn mạnh: đổi mới mạnh mẽ và đồng bộ mục tiêu, chương trình, nội dung, phương pháp, hình thức giáo dục, đào tạo theo hướng coi trọng phát triển năng lực và phẩm chất của người học. Để đáp ứng yêu cầu đổi mới này thì chương trình giáo dục phổ thông mới đã được Bộ hướng dẫn sẽ biên soạn bổ sung những nội dung giáo dục của địa phương, bao gồm "những 
vấn đề cơ bản hoặc thời sự về văn hóa, lịch sử, địa lí, kinh tế, xã hội, môi trường, hướng nghiệp...Trong chương trình giáo dục phổ thông năm 2018, chương trình giáo dục địa phương tiếp tục được đề cập. Theo đó khung chương trình tổng thể sẽ bao gồm các chủ đề chính, được phân theo ba nhóm chủ đề, bao gồm: i) Văn hoá, lịch sử, truyền thống của địa phương; ii) Địa lý, kinh tế, hướng nghiệp của địa phương; và iii) Chính trị-xã hội, mội trường của địa phương.

Tuy nhiên, nhiều chính sách cho các nhóm DTTS được cho là thiếu đầy đủ và phù hợp [10], không đạt được mục tiêu thu hẹp bất bình đẳng giữa nhóm dân tộc đa số và thiểu số [11]. Ngoài ra, nhiều chương trình và dự án còn chồng chéo hoặc quá chung chung đối với các dân tộc thiểu số [10]. Đặng Hải Anh (2012) khẳng định rằng hiệu quả và lợi ích của các chương trình hoặc dự án hiếm khi được đánh giá, và các cha mẹ người DTTS ít có cơ hội tham gia vào việc lập kế hoạch các dự án phát triển, hiếm khi tìm hiểu những lợi ích mong đợi của các dự án khi chúng được thực hiện [12].

Trong một số nghiên cứu về học sinh dân tộc thiểu số ở các tỉnh miền núi khó khăn, nhiều nghiên cứu chỉ ra rằng học sinh dân tộc thiểu số phải tiếp thu một lượng kiến thức đáng kể ở trường, nhưng các em gặp rất nhiều khó khăn trong việc áp dụng những kiến thức và kỹ năng đó vào trong thực tế bối cảnh địa phương. Sự cộng hưởng giữa kiến thức học đường và thực hành trong thực tế sống hàng ngày của học sinh dân tộc thiểu số và cộng đồng của họ còn rất hạn chế $[3,4,11,12]$.

Có thể thấy vẫn còn nhiều hạn chế, nghi vấn về tính ứng dụng và sự phù hợp của các chương trình, dự án giáo dục DTTS tại nhiều địa phương. Mặc dù các chính sách này có tham chiếu đến cách tiếp cận ngôn ngữ, văn hoá, tri thức bản địa, nhưng còn có sự mâu thuẫn trong quá trình triển khai, áp dụng trong trường học.

Trong khoa học nghiên cứu, nhiều lí thuyết giáo dục đã và đang không ngừng ra đời, phát triển nhằm thu hẹp khoảng cách giáo dục giữa các nhóm dân tộc, giữa các chủng tộc và màu da. Trong phạm vi bài viết này, tác giả sẽ trình bày một trong những cách tiếp cận giáo dục đang được chú ý ở nhiều nước phát triển, hướng đến các nhóm đối tượng da màu, tầng lớp có thu nhập thấp, trẻ em là người DTTS hoặc nhóm dễ bị tổn thương trong xã hội, nhưng còn rất mới mẻ ở Việt Nam: cách tiếp cận giáo dục dựa vào quỹ tri trức của học sinh (Funds of Knowledge) [13].

Cụ thể trong bài viết này, tác giả trình bày về khái niệm, đặc điểm của giáo dục dựa vào quỹ tri trức của học sinh, ý nghĩa và tác dụng của cách tiếp cận này đối với giáo dục, đặc biệt cho các nhóm đối tượng "yếu thế" trong xã hội, cũng như phương pháp tiếp cận của nó trong dạy và học. Trên cơ sở đó, tác giả đưa ra những luận bàn và liên hệ tới giáo dục DTTS và miền núi tại Việt Nam. Mục đích bài viết là nhằm cung cấp những vấn đề lý thuyết có tính hệ thống hoá về cách tiếp cận giáo dục dựa vào quỹ tri trức của học sinh và gợi ý những giải pháp góp phần giải quyết những thách thức đối với giáo dục DTTS tại Việt Nam. Bài viết cũng mở ra những hướng nghiên cứu mới để các nhà khoa học giáo dục trong nước có thể bàn luận, tìm hiểu, qua đó có những tiếp cận với sự phát triển của xu thế giáo dục thế giới, dựa trên mục tiêu "không để trẻ em nào bị bỏ lại phía sau".

\section{Tổng quan nghiên cứu}

\subsection{Nguồn gốc phát triển của giáo dục dụa vào quỹ tri thúc của hoc sinh (Funds of Knowledge)}

Vào cuối những năm 1980 và đầu những năm 1990, nhóm các nhà nghiên cứu bao gồm Luis Moll, Norma González, James Greenberg và Carlos Vélez-Ibáñez tại Đại học Arizona, Tucson, Hoa Kỳ đã báo cáo về một loạt các phương pháp thực hành liên quan đến các khái niệm giáo duc dưa vào quỹ tri thúc của học sinh (GDDVQTT)-Funds of knowledge (FoK) trong môi trường trường học [14-16].

Những nghiên cứu của nhóm tác giả này đã có ảnh hưởng lớn trong việc đề cao và phát triển sự hiểu biết về tri thức bản địa-địa phương, kiến thức và thực hành ngoài nhà trường, những giá trị văn hoá trong cộng đồng học sinh song ngũ người Mỹ gốc Mexico và 
người Latinh ở Tucson, Arizona, Hoa Kỳ. Nghiên cứu này nhằm mục đích xoá bỏ những quan điểm thiếu hụt, định kiến về những học sinh xuất thân từ những hộ gia đình thường bị coi là "nghèo" không chỉ về mặt kinh tế mà còn về nguồn kiến thức và kĩ năng cho con cái của họ [13]. GDDVQTT làm nổi bật những tri thức văn hóa đa dạng, phong phú, và kinh nghiệm sống mà các hộ gia đình tích luỹ trong lao động sản xuất, từ đó giúp giáo viên có thể dựa vào đó để nâng cao khả năng học tập cho học sinh.

\subsection{Vai trò, ý nghĩa của giáo dục dụa vào quỹ tri thức của hoc sinh}

GDDVQTT tập trung vào kết nối giữa tri thức của học sinh được hình thành trong đời sống, lao động sản xuất, văn hoá trong gia đình với những tri thức mang tính học thuật trong trường học. Giáo viên và học sinh là người thực hiện sự kết nối này thông qua những vai trò khác nhau. Giáo viên không đơn giản chỉ là người dạy, mà đóng vai trò như một nhà nghiên cứu (teacher-researcher) [17]. Phương pháp này tạo nên một hình thái quan hệ học tập mới, phá vỡ mô hình dạy học vốn tồn tại khá lâu theo hệ hình từ trên xuống (top-down), thay vào đó là hệ hình mang tính chia sẻ, mạng lưới, trong đó cả giáo viên, học sinh, cha mẹ học sinh cùng tham gia vào hoạt động học tập, trong đó người học sẽ trở thành trung tâm của mạng lưới học tập.

Do đó GDDVQTT được nhiều nhà giáo dục học cho rằng có thể giải quyết các vấn đề giáo dục hiện nay đối với nhóm học sinh là DTTS, da mầu, học sinh nhập cư, hoặc nhóm xuất thân từ tầng lớp có thu nhập trong xã hội. Đó là các vấn đề:

i) Nâng cao kết quả học tập của những học sinh thường bị đánh giá thấp bởi nền văn hóa thống trị trong hệ thống trường học truyền thống;

ii) Cải thiện mối quan hệ và hợp tác giữa học sinh/gia đình với giáo viên/nhà trường thông qua việc khám phá quỹ tri thức (FoK) của học sinh từ các chuyến đến thăm nhà học sinh;

iii) Tạo nên những đổi mới trong thực hành giảng dạy bằng cách thiết kế các bài giảng dựa trên quỹ tri thức FoK của học $\sinh [18,19]$.

\section{3. Đặc điểm và quy trình chung của giáo dục dưa vào quỹ tri thúc của họ sinh}

a) Phương pháp xác định quỹ tri thức của học sinh

Theo Moll (2014), trong số các phương pháp tiếp cận đa dạng hiện này, tới thăm nhà học sinh là phương pháp điều tra phổ biến, đặc trưng của cách tiêp cận quỹ tri thức $\mathrm{FoK}$ của học sinh [17]. Dưới sự hướng dẫn của các nhà nghiên cứu, giáo viên sẽ đến thăm các hộ gia đình của học sinh để tìm hiểu và thu thập thông tin từ gia đình của họ thông qua lăng kính dân tộc học [18]. Sau đó "nhóm nghiên cứu" sẽ được thành lập, trong đó giáo viên cùng các chuyên gia và nhà nghiên cứu thảo luận và đánh giá, xử lý thông tin thu thập được từ học sinh và gia đình họ để sử dụng làm kiến thức trong dạy học lớp học [17].

González và đồng nghiệp của ông đã mô tả quá trình bao gồm hai bước chính sau:

Bước 1: trước khi tới thăm nhà học sinh: giáo viên dưới sự hướng dẫn của các nhà nghiên cứ được đào tạo về cách tiếp cận các hộ gia đình theo phương pháp dân tộc học;

Bước 2: trong quá trình tới thăm nhà: bảng câu hỏi và các hướng dẫn phỏng vấn được chuẩn bị nhằm mang lại những kết quả rõ ràng cho bước tiếp theo là bước tiến hành nghiên cứu trong nhóm nghiên cứu [18].

Cần lưu ý là việc thăm nhà của giáo viên trong cách tiếp cận này khác với việc thăm nhà các phụ huynh học sinh vì mục đích học tập hay hành vi, thái độ trong quá trường học của con cái họ [17]. Ví dụ, trong một dự án của Cremin và các cộng sự (2012) nghiên cứu mối quan hệ của việc đọc, viết hàng ngày của học sinh và phương pháp tiếp cận quỹ tri thức FoK, giáo viên đã tiến hành thăm nhà học sinh để tìm hiểu về lịch sử gia đình và việc thực hành đọc, viết của chính học sinh ở nhà. Cuối cùng, dựa trên kiến thức và hiểu biết của học sinh mà giáo viên thu thập được từ các chuyến thăm nhà, giáo viên xây dựng kiến thức mới dựa trên thực tiễn lớp học và mối quan hệ giữa gia đình và nhà trường [20].

Phương pháp thăm nhà học sinh mang lại những lợi ích khác nhau cho quá trình dạy và 
học. Đầu tiên, các chuyến thăm nhà giúp giáo viên hiểu sâu sắc hơn về điều kiện sống và lối sống hàng ngày của học sinh, mở ra cho giáo viên một góc nhìn mới về văn hoá, công nhận và tôn trọng giá trị văn hoá đời sống của cộng đồng học sinh, đồng thời phát triển mối quan hệ mới giữa giáo viên, phụ huynh và học sinh thông qua sự tin tưởng lẫn nhau $[18,21]$. Đây được coi là chìa khóa ban đầu trong cách tiếp cận FoK của học sinh [22].

Thứ hai, thông qua các chuyến thăm nhà, giáo viên trở thành người học hoặc nhà nghiên cứu để tìm hiểu về nguồn tri thức của học sinh và gia đình họ, từ đó tiến hành đổi mới phương pháp giảng dạy trong môi trường nhà trường $[13,19]$.

b) Các yếu tố cấu thành của cách tiếp cận dựa vào quỹ tri thức của học sinh

Theo Moll (2014), phương pháp tiếp cận FoK bao gồm ba yếu tố liên quan (Hình 1): i) Nghiên cứu hộ gia đình (thông qua cách tiếp cận dân tộc học) - trong đó giáo viên sẽ đến thăm gia đình học sinh tại nhà; ii) Giáo viên phân tích lớp học, hoặc nghiên cứu các phương pháp thực hành trong lớp học mới; và iii) nhóm nghiên thảo luận về lý thuyết (phương pháp tiếp cận $\mathrm{FoK}$, tài liệu dân tộc học), phương pháp và thu thập dữ liệu, và các mối liên quan đến nghiên cứu hộ gia đình và lớp học [14].

Moll (2014) cũng cho rằng nhóm nghiên cứu được coi như một "cấu trúc trung gian" (mediating structure) kết nối phân tích hộ gia đình và các hoạt động trong lớp học. Nhóm nghiên cứu có nhiệm vụ chuẩn bị cho các chuyến thăm hộ gia đình cho giáo viên và tham gia vào phân tích các dữ liệu thu thập được từ hộ gia đình thành tài nguyên tri thức phục vụ cho việc giảng dạy.

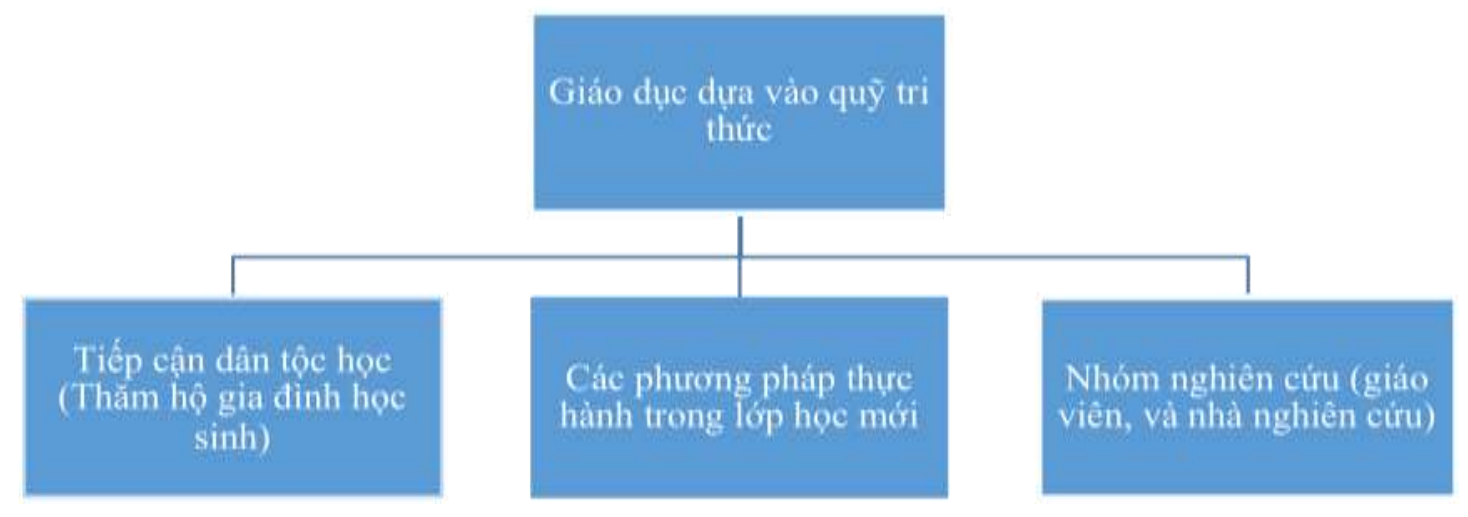

Hình 1. Các yếu tố cấu thành của cách tiếp cận dựa vào quỹ tri thức.

c) Quy trình chung của dạy học dựa vào quỹ tri thức

Một bài học theo cách tiếp cận quỹ tri thức FoK của học sinh thường được bắt đầu với một tình huống hay vấn đề cụ thể xoay quanh đời sống gia đình và cộng đồng của học sinh - bước này có ý nghĩa như đặt nền móng để phát triển và tiến hành các hoạt động học của học sinh. Nó thúc đẩy nhu cầu học tập ở học sinh và khuyến khích các em tìm kiếm, khám phá, chia sẻ thông tin với giáo viên và bạn học. Học sinh được chủ động trong việc phát hiện, cung cấp và thảo luận các ý tưởng, thông tin, lý thuyết để giải quyết nhiệm vụ bài học đặt ra.
Đối với giáo viên, họ sẽ có vai trò như người đại diện trong việc xác định lại môi trường lớp học để ở đó sẽ bao gồm cả học sinh, phụ huynh, gia đình và cộng đồng trong việc hình thành và phát triển kiến thức, kĩ năng cho học sinh [23-26] (Hình 2).

d) Một số ví dụ về giáo dục dựa vào quỹ tri thức của học sinh được sử dụng trong dạy học

Vi $d u$ 1: McIntyre, Swazy và Greer (2001) đã mô tả cách hai giáo viên đến thăm nhà các học sinh của họ ở vùng nông thôn Kentucky để hiểu rõ hơn về quỹ tri thức $\mathrm{FoK}$ của học sinh. Sau những chuyến thăm này, hai giáo viên đã thiết kế một loạt các bài học đọc, viết và làm 
toán xoay quanh một sự kiện lớn hàng năm của trường: "Ngày nông nghiệp". Giáo viên kết nối chương trình giảng dạy với cuộc sống của học sinh bằng cách khám phá kiến thức sâu rộng và khả năng canh tác, làm nông nghiệp của học sinh và gia đình họ (ví dụ: tốc độ phát triển của các loại cây khác nhau). Trong ví dụ này, các giáo viên đã sử dụng ba chiến lược để bối cảnh hóa chương trình giảng dạy. Đầu tiên, các giáo viên thiết kế các hoạt động giảng dạy dựa trên những kiến thức về nông nghiệp mà học sinh đã biết từ gia đình, cộng dồng và trường học (ví dụ: sử dụng sách về nông nghiệp rất phổ biến với học sinh).

Thứ hai, hai giáo viên này hỗ trợ học sinh kết nối và áp dụng kiến thức của họ vào các hoạt động trong lớp (ví dụ: liên hệ kiến thức về cách gia đình họ trồng cây với vòng đời của thực vật và sau đó là vòng đời của động vật). Thứ ba, những giáo viên này tạo cơ hội cho phụ huynh và các thành viên trong cộng đồng tham gia vào các hoạt động hướng dẫn trong lớp học (mời một số phụ huynh giúp đỡ trong ngày nông nghiệp của trường) [26].
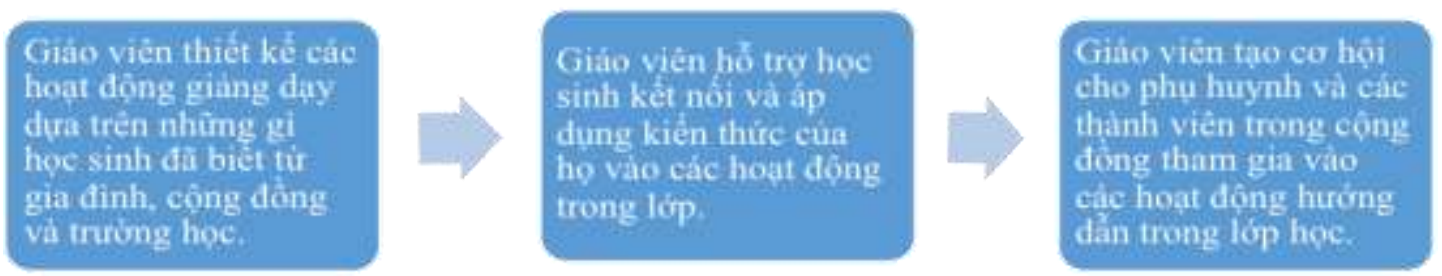

Hình 2. Quy trình chung của dạy học dựa vào quỹ tri thức của học sinh.

$V i$ du 2: một số nghiên cứu đã được thực hiện để nhấn mạnh tài năng, niềm đam mê và sở thích của học sinh như một quỹ tri thức của họ nhằm cung cấp những kiến thức và thực hành trong trường học [27-30]. Ví dụ, Hedges và các cộng sự (2011) đã xác định quỹ tri thức FoK của học sinh dựa trên các thói quen và các hoạt động trong gia đình của họ (như làm việc nhà, nấu ăn, đi du lịch cùng gia đình), hay những trải nghiệm ở trường học (sở thích và hoạt động cùng bạn bè, ngôn ngữ, trải nghiệm) và trong cộng đồng (các sự kiện văn hóa như tiệc sinh nhật, năm mới của Trung Quốc và các xu hướng văn hoá phổ biến). Dòng nghiên cứu này đã chỉ ra cho giáo viên về cách nhận ra sở thích và đam mê của trẻ em và sử dụng chúng để mở rộng chương trình giảng dạy. Ví dụ, trường hợp của một trong những giáo viên đã vận dụng sự đam mê của học sinh đối với seri truyện tranh "Ninja Rùa đột biến tuổi teen" (Teenage Mutant Ninja Turtles) để phát triển kỹ năng đọc viết của họ [31].

Vi du 3: Moll (1992) mô tả công việc của một giáo viên, trong suốt một học kỳ, đã mời khoảng 20 phụ huynh và những người khác trong cộng đồng đóng góp trí tuệ vào việc xây dựng các bài học. Giáo viên này đã sử dụng nhiều quỹ tri thức FoK khác nhau, bao gồm quỹ tri thức của chính học sinh, cha mẹ và người thân của họ. Sau đó, những tri thức này lại trở thành một phần nhiệm vụ của học sinh trên lớp hoặc trọng tâm bài học. Trong mô hình này, giáo viên đã phát triển một mạng lưới xã hội để truy cập vào quỹ tri thức $\mathrm{FoK}$ của học sinh cho các mục đích học thuật, đồng thời thu hút học sinh tham gia vào các nhiệm vụ học tập và cung cấp những trải nghiệm học tập chân thực, có ý nghĩa phù hợp với cuộc sống của học sinh [32].

\section{Phương pháp nghiên cứu}

Để thực hiện đánh giá toàn diện đầy đủ các tài liệu nghiên cứu về việc sử dụng quỹ tri thức của học sinh (Funds of knowledge) trong chương trình giảng dạy của trường, tác giả đã sử dụng các công cụ tìm kiếm và cơ sở dữ liệu của ERIC, PsycINFO, Google Scholar và Social Science Citation Index (Chỉ số trích dẫn Khoa học Xã hội) với cụm từ tìm kiếm "quỹ kiến thưcc" (Funds of knowledge).

Đầu tiên, tác giả đã giới hạn việc tìm kiếm các tạp chí và bài báo xuất hiện trong thập kỷ 
qua (2009-2019), vì những tạp chí này tập trung vào các bài đánh giá cập nhật nhất về vấn đề nghiên cứu. Tuy nhiên, các nghiên cứu mang tính bước ngoặt trước đó liên quan đến khung lý thuyết này cũng được tham khảo $[13,18]$.

Thứ hai, đánh giá bao gồm nghiên cứu liên quan đến thực hành của giáo viên dựa vào quỹ tri thức FoK của học sinh, đối với tất cả giáo viên ở các cấp học khác nhau. Do đó, các cụm từ tìm kiếm bao gồm học sinh (students/children), quỹ tri thuic (Funds of knowledge), giáo viên (teachers), giáo viên tiểu học (primary teachers), và đào tạo giáo viên (teacher education), thực hành giảng dạy (teaching practices).

Thứ ba, các thuật ngữ liên quan đến giáo viên (teachers), đào tạo giáo viên (teacher education), thưc hành giảng dạy (teaching practices) sẽ được kết hợp với các thuật ngữ liên quan đến quỹ tri thức ngoài nhà trường và các thế mạnh, sở thích của học sinh dân tộc thiểu số và gia đình của họ. Các cụm từ tìm kiếm sẽ bao gồm học sinh dân tộc thiểu số (ethnic minority students), quỹ tri thức (Funds of knowledge), cha me (minority parents/ family). Mặc dù các bài báo liên quan đến FoK của học sinh dân tộc thiểu số, cộng đồng dân tộc thiểu số được ưu tiên, các cụm từ tìm kiếm bao gồm học sinh/cộng đồng có hoàn cảnh khó khăn (disadvantaged students/community), hoặc hộ gia đinh có thu nhập thấp (low-income students) cũng sẽ được sử dụng.

Thứ 4 , phạm vi địa lý trong nghiên cứu này được mở rộng bao gồm các nước, các khu vực khác nhau, trong đó có Việt Nam nhằm cung cấp cái nhìn sâu sắc về lĩnh vực nghiên cứu và tính ứng dụng của phương pháp này vào bối cảnh Việt Nam.

\section{Kết quả nghiên cứu và bình luận}

4.1 Vận dụng cách tiếp cận giáo duc dụa vào quỹ tri thức FoK vào Viẹt Nam cho họ sinh dân tộc thiểu số vùng cao

Thứ nhất, giáo dục DTTS tại Việt Nam đang phải đối mặt với rất nhiều vấn đề, bao gồm: i) Chương trình dạy học và sách giáo khoa còn nhiều hạn chế, chưa phù hợp với học sinh DTTS, không gắn với ngôn ngữ, văn hóa và tri thức trong đời sống hàng ngày của học sinh và cộng đồng của họ $[3,33,34]$; ii) Thiếu đề cao giá trị ngôn ngữ mẹ đẻ của học sinh DTTS trong môi trường nhà trường $[35,36]$; iii) phương pháp dạy học thiếu "văn hoá đáp ứng" [37, 38]; iv) Thiếu nguồn lực giáo viên, đặc biệt giáo viên có chất lượng cao và giáo viên bản địa $[12,39]$; và v) Thiếu góc nhìn đa dạng về văn hoá, tín ngưỡng và đời sống của người DTTS [40, 41].

Trong khi cách tiếp cận GDDVQTT đã được nhiều nước nghiên cứu và đưa vào ứng dụng thì ở Việt Nam vẫn còn rất mới mẻ. Tại Việt Nam, tính đến thời điểm hiện tại chỉ có một nghiên cứu duy nhất của Hedges et al. (2016) tìm hiểu về mối quan hệ hợp tác giữa giáo viên tiểu học người Kinh và cha mẹ học sinh người Bah'nar dựa trên khai thác quy tri thức FoK của học sinh và cộng đồng họ [42].

Trong khi đó, các nhà khoa học, giáo dục, hoạch định chính sách giáo dục ở Việt Nam không ngừng kêu gọi thực hiện đổi mới chương trình dạy học, phương pháp dạy học nhằm nâng cao chất lượng giáo dục cho học sinh DTTS, thu hẹp khoảng cách giáo dục giữa nhóm DTTS và dân tộc đa số (người Kinh). Do đó, việc tìm hiểu và vận dụng cách tiếp cận GDDVQTT là cần thiết và phù hợp hoàn cảnh của giáo dục DTTS ở Việt Nam hiện nay.

Thứ hai, Thomson và Hall (2008) cho rằng định nghĩa quỹ tri thức FoK của học sinh còn bị hạn chế vì các quỹ tri thức FoK của học sinh và các hộ gia đình rất đa dạng, và bất kỳ các quỹ tri thức FoK của học sinh đều có thể đóng góp vào kiến thức trong nhà trường [43]. Do đó, nghiên cứu GDDVQTT tại cộng đồng DTTS ở Việt Nam hi vọng sẽ khám phá thêm nhiều loại quỹ tri thức FoK cuả học sinh và gia đình họ, từ đó có thể sử dụng làm tài nguyên giáo dục, xây dựng kiến thức trong việc giảng dạy học sinh DTTS tại Việt Nam và đóng góp vào khung lý thuyết GDDVQTT nói chung.

Dưới đây là một số ví dụ về khai thác quỹ tri thức của học sinh DTTS có thể cân nhắc để 
khai thác và sử dụng trong việc thiết kế các bài học theo cách tiếp cận trên:

Vi du 1: tri thức, kinh nghiệm trồng trọt, chăn nuôi, làm lâm nghiệp trong điều kiện tự nhiên khó khăn, hay trồng lúa trên ruộng bậc thang là những tài nguyên tri thức quan trọng của cha mẹ và học sinh người DTTS. Những kiến thức ngoài nhà trường này liên quan trực tiếp tới các bài học có nội dung về trồng trọt, chăn nuôi, khoa học, thủ công trong chương trình giảng dạy nhà trường ở các môn học như Văn học, Lịch sử và Địa lý, Sinh học, Hoạt động trải nghiệm sáng tạo. Vì vậy đây có thể sẽ là nguồn tài nguyên tri thức quan trọng để giáo viên có thể khám phá và vận dụng vào trong giảng dạy các môn học trong nhà trường.

Vi $d u$ 2: tri thức, tài nguyên về ngôn ngữ tiếng mẹ đẻ, thơ ca, chuyện dân gian của học sinh DTTS cũng là một nguồn tài nguyên tri thức cần khai thác và đưa vào sử dụng trong dạy học. Thực tế, khi dạy học học sinh DTTS, rất nhiều giáo viên thừa nhận rằng khi họ có khả năng khai thác, sử dụng kết hợp ngôn ngữ tiếng mẹ đẻ của học sinh DTTS và ngôn ngữ phổ thông (tiếng Việt) trong giảng dạy thì khả năng tham gia vào các hoạt động học của học sinh được cải thiện đáng kể, học sinh hiểu bài nhanh hơn và chất lượng dạy - học được nâng cao, đặc biệt trong các môn học có khối lượng kiến thức học thuật lớn như Văn học, Toán học. Trong các môn học như Văn học, Lịch sử thông qua các chủ đề Văn học, Lịch sử địa phương giáo viên có thể khai thác nguồn tài nguyên thơ ca, chuyện dân gian từ cha mẹ của học sinh DTTS như một nguồn tài nguyên tri thức ngoài nhà trường để đưa vào dạy học cho học sinh, đặc biết là học sinh DTTS bậc tiểu học vì đây là nhóm gặp nhiều rào cản lớn nhất về mặt ngôn ngữ khi tới trường.

Vi du 3: các giá trị bản sắc văn hoá dân tộc của cộng đồng các DTTS tại Việt Nam rất phong phú, đa dạng, giàu bản sắc (thêu thùa, dệt thổ cẩm, đan lát, các điệu múa, các dụng cụ âm nhạc hay trò chơi dân gian,...). Những nguồn tài nguyên này nếu biết khai thác sẽ là tiềm năng giáo dục phục vụ cho các môn học như Thể chất, Nghệ thuật, Hoạt động trải nghiệm sáng tạo, Thủ công - kỹ thuật,... Yêu cầu đặt ra là cần có sự phối hợp chặt chẽ giữa nhà trường/giáo viên và học sinh/cha mẹ học sinh nhằm khai thác những nguồn tài nguyên này một cách hiệu quả, chuyển đổi những tài nguyên tri thức này từ ngoài cộng đồng thành tài nguyên kiến thức giảng dạy trong nhà trường.

Khung lý thuyết GDDVQTT là lời kêu gọi phát triển chương trình dạy học dựa trên tài nguyên tri thức hiện có của học sinh và gia đình, cộng đồng học sinh. Việc tập trung vào các chuyển đổi đối tượng sư phạm từ giáo viên sang lấy học sinh làm trung tâm và sự cần thiết tăng cường mối quan hệ bền chặt giữa giáo viên và học sinh đang ngày càng củng cố thêm tính khả thi của cách tiếp cận GDDVQTT.

\subsection{Thách thức khi áp dụng cách tiếp cận giáo dục dựa vào quỹ tri thức FoK vào Việt Nam}

Thứ nhất, sự khác biệt về ngôn ngữ giữa học sinh DTTS và ngôn ngữ của giáo viên Kinh (Tiếng Việt) có thể coi là một trong những rào cản lớn nhất trong việc tiếp cận học sinh DTTS và cha mẹ các em. Trong khi việc xây dựng mối quan hệ lâu dài, tin tưởng lẫn nhau giữa giáo viên, học sinh, và cha mẹ học sinh được coi là nền tảng cho cách tiếp cận quỹ tri thức $\mathrm{FoK}$ [18], thì các giáo viên, đặc biệt là giáo viên Kinh dường như đang phải đối mặt với những thách thức trong việc tạo niềm tin, và mối quan hệ gần gũi với học sinh DTTS và cha mẹ của họ bởi những rào cản ngôn ngữ này.

Thứ hai, những suy nghĩ "thiếu hụt về văn hoá" (cultural deficit thinking) về học sinh DTTS và bản sắc của người DTTS cũng là rào cản đối với nhiều giáo viên người Kinh trong việc đề cao và sử dụng quỹ tri thức FoK của học sinh DTTS. Thêm vào đó thiếu nguồn lực giáo viên, đặc biệt giáo viên là người DTTS và giáo viên có thâm niên gắn bó lâu năm với vùng cao, vùng DTTS cũng là một trở ngại đáng kể.

Thứ ba, một trong ba yếu tố cấu thành nên cách tiếp cận dựa vào quỹ tri thức FoK là việc hình thành các nhóm nghiên cứu (study group) $[13,17,18]$. Tuy nhiên trong bối cảnh giáo dục vùng cao tại Việt Nam, đang thiếu sự hợp tác 
giữa giáo viên và các nhà nghiên cứu, các chuyên gia về dân tộc học. Thêm vào đó, các chương trình tập huấn, bồi dưỡng cho giáo viên liên quan đến khám phá các nguồn tài nguyên tri thức FoK của học sinh còn rất hạn chế. Đồng thời, những khó khăn về cơ sở vật chất và nguồn lực để hỗ trợ giáo viên cũng là yếu tố thách thức đối với việc dạy học theo hướng tiếp cận này.

\section{Kết luận}

Cách tiếp cận GDDVQTT hiện đã được phát triển trong nhà trường ở nhiều nước phát triển. Tại Việt Nam cách tiếp cận này cũng đã và đang được thực hiện trong một số trường vùng cao, vùng DTTS dưới một số hình thức thông qua các dự án giáo dục DTTS cấp quốc gia. Trong giới hạn bài viết này, người viết mới chỉ tổng kết, hệ thống hoá lại cơ sở lý thuyết chung về cách tiếp cận GDDVQTT. Mặc dù đã có sự liện hệ và những gợi mở ban đầu về cách tiếp cận này với giáo dục DTTS tại Việt Nam, song cần có thêm nhiều nghiên cứu về phương pháp này, đặc biệt là những nghiên cứu có tính ứng dụng thực tiễ்n.

Rios-Aguilar và các cộng sự (2011) đã chỉ ra rằng rất ít nghiên cứu đề cập và thảo luận về mối quan hệ giữa quỹ tri thức FoK của học sinh và các vấn đề về quyền lực, giai cấp xã hội, hệ tư tưởng và phân biệt chủng tộc, và cách nó có thể cản trở những nỗ lực của giáo viên trong việc đưa quỹ tri thức FoK của học sinh vào bối cảnh trường học [45]. Do đó, với bối cảnh văn hoá - xã hội Việt Nam, dưới ảnh hưởng của Nho giáo và văn hoá phương đông, cùng với sự đa dạng trong văn hoá, tôn giáo, tín ngưỡng của các nhóm DTTS, cần xem xét, chú ý đến những đặc điểm riêng cuả Việt Nam để cho cách tiếp cận này trở nên khả thi và phù hợp tại Việt Nam.

Những nghiên cứu tiếp theo có thể tìm hiểu bao gồm:

i) Khảo sát những phương pháp dạy học dựa trên cách tiếp cận GDDVQTT mà giáo viên đã sử dụng (nếu có) trong lớp học để dạy cho học sinh DTTS. Nếu có thì bằng những chiến lược dạy học nào mà giáo viên đã sử dụng để có thể khai thác, vận dụng những tài nguyên tri thức ngoài nhà trường của học sinh DTTS vào trong dạy học kiến thức trong nhà trường;

ii) Nghiên cứu, tìm hiểu những nguồn tài nguyên tri thức nào của học sinh DTTS và cha mẹ học sinh để đưa vào giảng dạy tích hợp với một số môn học phù hợp trong nhà trường;

iii) Nghiên cứu khai thác tài nguyên tri thức bản địa của học sinh DTTS và cộng đồng như nguồn tài liệu cho việc biên soạn các chủ đề trong tài liệu giáo dục địa phương phục vụ cho chương trình giáo dục phổ thông mới năm 2018.

Những nghiên cứu cụ thể và mang tính thực tiễn như trên có thể trở thành tài liệu phong phú để áp dụng cách tiếp cận GDDVQTT ở cho học sinh DTTS ở Việt Nam ở các bậc học, góp phần phát triển, mở rộng cách tiếp cận này, cũng như nâng cao hiệu quả ứng dụng của nó trong dạy học đối với học sinh DTTS, từ đó góp phần nâng cao chất lượng dạy-học cho học sinh DTTS tại Việt Nam.

\section{Tài liệu tham khảo}

[1] H. C. Truong, Schooling as Lived and Told: Contrasting Impacts of Education Policies for Ethnic Minority Children in Vietnam Seen from Young Lives Surveys (Background Paper Prepared for the Education for All Global Monitoring Report 2010 Reaching the Marginalized), UNESCO,

https://assets.publishing.service.gov.uk/media/57 a08b79e5274a27b2000b77/SchoolingasLivedand Told.pdf/, 2009 (accessed on: April 15 ${ }^{\text {th }}, 2021$ ) (in Vietnamese).

[2] J. D. London, Education in Vietnam, Institute of Southeast Asian Studies, 2011.

[3] N. T. Tran, Factors Associated with Low Educational Motivation Among Ethnic Minority Students in Vietnam, Ritsumeikan Journal of Asia Pacific Studies, Vol. 32, 2013, pp. 124-136.

[4] T. T. H. Vu, Ethnic Minority Children's and Adults' Perceptions and Experiences of Schooling in Vietnam: A Case Study of the Cham H'Roi, In M. Bourdillon, J. Boyden (Eds.), Growing up in Poverty Findings from Young Lives, Palgrave Macmillan, 2014, pp. 225-244.

[5] UNESCO, The Cultural Diversity Programming Lens: A Practical Tool to Integrate Culture in Development - Pedagogical Guide, UNESCO, http://www.unesco.org/new/en/culture/themes/cu lture-and-development/the-cultural- 
diversitylens/, 2011 (accessed on: April 15 ${ }^{\text {th }}$ 2021) (in Vietnamese).

[6] World Bank, Vietnam-High Quality Education for All by 2020: Overview/report (English), World Bank, http://documents.vsemirnyjbank.org/curated/ru/4 16151468320084130/pdf/680920v10WP0P10

duc0tap10Engl012012.pdf/, 2011 (accessed on: April $15^{\text {th }}, 2021$ ) (in Vietnamese).

[8] UNICEF, Evaluation of Unicef-supported Moet's Initiative of Mother Tongue Based Bilingual Education in Vietnam 2006 - 2014, UNICEF, https://www.unicef.org/evaldatabase/files/UNIC EF_VN_MTBBE_Final_Evaluation_Report_Viet nam_2015-031.pdf/, 2015 (accessed on: April $15^{\text {th }}, 2021$ ) (in Vietnamese).

[9] World Bank, Implementation Completion and Results Report (IDA-46080) on a Credit in the Amount of SDR 85.4 Million (US\$127 Million Equivalent) to the Socialist Republic of Vietnam for a School Education Quality Assurance Program, World Bank,

http://documents.worldbank.org/curated/en/5315 $11498478745258 / \mathrm{pdf} /$ ICR0000410306232017.pdf/, 2017 (accessed on: April 15 $5^{\text {th }}$, 2021) (in Vietnamese).

[10] World Bank and MOET, Ethnic Minority Plan - School Education Quality Project, World Bank,Fhttp://documents.worldbank.org/curated/e n/574571468130208185/pdf/IPP3360v30Ethn1h 131final0Box0338876.pdf/, 2009 (accessed on: April 15 ${ }^{\text {th }}, 2021$ ) (in Vietnamese).

[11] B. Baulch, T. K. C. Truong, D. Haughton, J. Haughton, Ethnic Minority Development in Vietnam, The Journal of Development Studies, Vol. 43, No. 7, 2007, pp. 1151-1176.

[12] H. C. Truong, Eliminating Inter-ethnic Inequalities? Assessing Impacts of Education Policies on Ethnic Minority Children in Vietnam, Young Lives, https://ora.ox.ac.uk/objects/uuid:155ecf7d-da6f4b50-b1d9-9dfb94c3b227/, 2011 (accessed on: April $\left.15^{\text {th }}, 2021\right)$ (in Vietnamese).

[13] H. A. Dang, A Widening Poverty Gap for Ethnic Minorities, In G. H. Hall, H. A. Patrinos (Eds.), Indigenous Peoples, Poverty, and Development, Cambridge University Press, 2012, pp. 274-309.

[14] L. C. Moll, C. Amanti, D. Neff, N. González, Funds of Knowledge for Teaching: Using a Qualitative Approach to Connect Homes and Classrooms, Theory Into Practice, Vol. 31, No. 2, 1992, pp. 132-141.

[15] C. G. V. Ibanez, Networks of Exchange Among
Mexicans in the U.S. and Mexico: Local Level Mediating Responses to National and International Trans-formations, Urban Anthropology, Vol. 17, No. 1, 1988, pp. 27-51.

[16] L. C. Moll, J. B. Greenberg, Creating Zones of Possibilities: Combining Social Contexts for Instruction, In L. C. Moll (Ed.), Vygotsky and Education: Instructional Implications and Applications of Sociohistorical Psychology, Cambridge University Press, 1990, pp. 319-348.

[17] N. González, Processual Approaches to Multicultural Education, The Journal of Applied Behavioral Science, Vol. 31, No. 2, 1995, pp. 234-244.

[18] L. Moll, L. S. Vygotsky and Education, New York: Routledge, 2014.

[19] N. González, L. C. Moll, K. Amanti, Funds of Knowledge: Theorizing Practices in Households, Communities, and Classrooms, Mahwah, Lawrence Erlbaum Associates, 2005.

[20] G. Rodriguez, Power and Agency in Education: Exploring the Pedagogical Dimensions of Funds of Knowledge, Review of Research in Education, Vol. 37, No. 1, 2013, pp. 87-120.

[21] T. Cremin, M. Mottram, F. Collins, S. Powell, R. Drury, Building Communities: Teachers Researching Literacy Lives, Improving Schools, Vol. 15, No. 2, 2012, pp. 101-115.

[22] M. Llopart, M. E. Guitart, Funds of Knowledge in $21^{\text {st }}$ Century Societies: Inclusive Educational Practices for Under-represented Students, A Literature Review, Journal of Curriculum Studies, Vol. 50, No. 2, 2018, pp. 145-161.

[23] M. R. Cortez, B. B. Flores, Sin Olvidar a Los Padres: Families Collaborating within School and University Partnerships, Journal of Latinos and Education, Vol. 8, No. 3, 2009, pp. 231-239.

[24] S. J. Basu, A. C. Barton, Developing a Sustained Interest in Science Among Urban Minority Youth, Journal of Research in Science Teaching, Vol. 44, 2007, pp. 466-489.

[25] A. Calabrese Barton, E. Tan, Funds of Knowledge and Discourses and Hybrid Space, Journal of Research in Science Teaching, Vol. 46, 2009, pp. 50-73.

[26] D. Henderson, L. Zipin, Bringing Clay to Life: Developing Student Literacy through Clay Animation Artwork to Tell Life-based Stories, In B. Prosser, B. Lucas, A. Reid (Eds.), Connecting Lives and Learning: Renewing Pedagogy in the Middle Years, Adelaide, South Australia: Wakefield Press, 2010, pp. 20-39.

[27] E. McIntyre, R. A. Swazy, S. Greer, Agricultural 
Eld Day, Linking Rural Cultures to School Lessons, In E. McIntyre, A. Rosebery, N. González (Eds.), Classroom Diversity, Connecting Curriculum to Students' Lives, Porstmouth, H: Heinemann, 2001, pp. 76-84.

[28] J. Andrews, W. Yee, Children's Funds of Knowledge and Their Real Life Activities: Two Minority Ethnic Children Learning in Out-ofschool Contexts, Educational Review, Vol. 58, 2006, pp. 435-449, http://doi.org/10.1080/00131910600971909.

[29] H. Hedges, Sophia's Funds of Knowledge: Theoretical and Pedagogical Insights, Possibilities and Dilemma, International Journal of Early Years Education, Vol. 23, No. 1, 2015, pp. 83-96, http://doi.org/10.1080/09669760.2014.976609.

[30] E. B. Moje, K. M. Ciechanowski, K. Kramer et al., Working Toward Third Space in Content Area Literacy: An Examination of Everyday Funds of Knowledge and Discourse, Reading Research Quarterly, Vol. 39, No. 1, 2004, pp. 38-70, http://doi.org/10.1598/RRQ.39.1.4.

[31] L. Zipin, S. Sellar, M. Brennan, T. Gale, Educating for Futures in Marginalized Regions: A Sociological Framework for Rethinking and Researching Aspirations, Educational Philosophy and Theory, Vol. 47, No. 3, 2013, pp. 227-246, http://doi.org/10.1080/00131857.2013.839376.

[32] H. Hedges, J. Cullen, B. Jordan, Early Years Curriculum: Funds of Knowledge as a Conceptual Framework for Children's Interests, Journal of Curriculum Studies, Vol. 43, No. 2, 2011, pp. 185-205, http://doi.org/10.1080/00220272.2010.511275.

[33] L. C. Moll, Bilingual Classroom Studies and Community Analysis: Some Recent Trends, Educational Researcher, Vol. 21, No. 2, 1992, pp. $20 \mathrm{e} 24$.

[34] World Bank, Report on Social Assessment and Proposed Bias Avoidance Framework for Development of Curriculum and Teaching Materials for Vulnerable Children, World Bank, http://documents.worldbank.org/curated/en/7180 61468334301767/pdf/SR690SR0P150050Box38 5425B00PUBLIC0.pdf/, 2014 (accessed on: April $15^{\text {th }}, 2021$ ) (in Vietnamese).

[35] T. K. T. Bui, An Investigation into the Use of Culturally Responsive Teaching Strategies: Teaching English to Muong Ethnic Minority Students at a Tertiary Institution in Vietnam Doctoral Dissertation, Victoria University of Wellington, Research Direct, https://researcharchive.vuw.ac.nz/xmlui/bitstrea $\mathrm{m} /$ handle $/ 10063 / 3227 /$ thesis.pdf? sequence $=2 /$, 2014_(accessed on: April 15 ${ }^{\text {th }}, 2021$ ) (in Vietnamese).

[36] L. H. Phan, H. H. Vu, B. Dat, Language Policies in Modern-day Vietnam: Changes, Challenges, and Complexities, In P. Sercombe, R. Tupas (Eds.), Language, Education, and Nation building: Assimilation and Shift in Southeast Asia, Palgrave Macmillan, 2014, pp. 232-244.

[37] T. N. T. Bui, T. H. N. Ngo, T. M. H. Nguyen, L. T. H. Nguyen, Access and Equity in Higher Education in Light of Bourdieu's Theories: A Case of Minority Students in Northwest Vietnam, In N. T. Nguyen, L. T. Tran (Eds.), Reforming Vietnamese Higher Education, Springer, 2019, pp. 149-169.

[38] T. Rheinländer, H. Samuelsen, A. Dalsgaard, F. Konradsen, Teaching Minority Children Hygiene: Investigating Hygiene Education in Kindergartens and Homes of Ethnic Minority Children in Northern Vietnam, Ethnicity and Health, Vol. 20, No. 3, 2015, pp. 258-272.

[39] P. T. Dang, W. A. Boyd, Renovating Early Childhood Education Pedagogy: A Case Study in Vietnam, International Journal of Early Years Education, Vol. 22, No. 2, 2014, pp. 184-196.

[40] T. D. Le, T. T. H. Nguyen, I. Jooren, Inequality in Educational Opportunities and Outcomes: Evidence from Young Lives Data in Vietnam, Young Lives,

https://www.younglives.org.uk/sites/www.young lives.org.uk/files/YL-CountryReport-

Vietnam.pdf/, 2016 (accessed on: April 15 ${ }^{\text {th }}$, 2021) (in Vietnamese).

[41] B. Baulch, T. M. H. Nguyen, T. T. P. Nguyen, T. H. Pham, Ethnic Minority Poverty in Vietnam, Federal Reserve Bank of St Louis, 2011.

[42] C. Lavoie, The Educational Realities of HMông Communities in Vietnam: The Voices of Teachers, Critical Inquiry in Language Studies, Vol. 8, No. 2, 2011, pp. 153-175.

[43] H. Hedges, M. Fleer, F. Fleer-Stout, T. B. H. Le, Aspiring to Quality Teacher-parent Partnerships in Vietnam: Building Localised Funds of Knowledge, International Research in Early Childhood Education, Vol. 7, No. 3, 2016, pp. 49-68.

[44] P. Thomson, C. Hall, Opportunities Missed and/or Thwarted? Funds of Knowledge Meet the English National Curriculum, The Curriculum Journal, No. 19, No. 2, 2008, pp. 87-103.

[45] C. R. R. Aguilar, J. Kiyama, M. Gravitt, L. C. Moll, Funds of Knowledge for the Poor and Forms of Capital for the Rich? A Capital Approach to Examining Funds of Knowledge, Theory and Research in Education, Vol. 9, No. 2, 2011, pp. 163-184. 